\title{
A scenario based project portfolio selection
}

\author{
Kamran Pourahmadi*, Siamak Nouri and Saeed Yaghoubi
}

School of Industrial Engineering, Iran University of Science and Technology, Tehran, Iran

\begin{tabular}{l}
\hline C H R O N I C L E \\
\hline Article history: \\
Received March 25, 2015 \\
Received in revised format June \\
12015 \\
Accepted June 172015 \\
Available online \\
June 18 2015 \\
\hline Keywords: \\
Project portfolio selection \\
Scenario planning \\
Uncertainty \\
\end{tabular}
A B S T R A C T

\begin{abstract}
One of the primary assumptions in many project portfolio selection is the availability of all parameters. However, in real-world cases, many parameters are under uncertainty and the exact values are unknown in advance. This paper presents a scenario based mathematical model for project portfolio selection when parameters are under uncertainty. The problem considers two objective functions where the first one maximizes the net present value while the second objective function is the minimization of the positive deviations from the allocation of resources. The second objective function is looking for project resource leveling. The resulted model is formulated as mixed integer programming and the problem is analyzed under different conditions.
\end{abstract}

\section{Introduction}

Selecting the right portfolio often helps minimization of relevant costs, which could lead to better profitability and this has been used in many areas such as research and development (R\&D) (Abbassi et al., 2014), information technology software development (Bardhan et al., 2010; Chiang \& Nunez, 2013; Rahmani et al., 2012; Müller et al., 2015), etc. Portfolio selection is one of the most important problems which human, companies and organizations are in dealing with (Hai-xiang \& Zhong-fei, 2009; Golmohammadi \& Pajoutan, 2011). Davoudpour et al. (2012) presented the results of developing a mathematical model for renewable technology portfolio selection at an oil industry R\&D center by maximizing support of the organization's strategy and values by balancing the cost/benefit of the entire portfolio. Ghorbani and Rabbani (2009) proposed a multi-objective algorithm for project selection problem by considering two objective functions to maximize total expected benefit of selected projects and minimize the summation of the absolute variation of devoted resource between each successive time periods. They also presented a meta-heuristic multi-objective to determine diverse locally nondominated solutions. The proposed algorithm was then compared with a well-known genetic algorithm, i.e. NSGA-II. Golmakani and Fazel (2011) considered constrained portfolio selection using particle swarm optimization. Liesiö et al. (2008) presented a robust portfolio modeling with incomplete cost

* Corresponding author.

E-mail address: pourahmadi@ind.iust.ac.ir (K. Pourahmadi) 
information and project interdependencies. Solak et al. (2010) investigated optimization of R\&D project portfolios under endogenous uncertainty.

Many project portfolio selection problems are dealt with uncertain parameters and we need to use different techniques such as robust optimization to handle uncertainty with input parameters (Huang \& Qiao, 2012). Vilkkumaa et al. (2014) presented optimal strategies for selecting project portfolios using uncertain value estimates. Hassanzadeh et al. (2014), for instance, used robust optimization for interactive multi-objective programming with imprecise information and as a case study they applied their method to R\&D project portfolio selection. Some people believe that successful project portfolio management is beyond project selection techniques and we need to understand the role of structural alignment (Kloppenborg, 2014; Kaiser et al., 2015).

Some people believe the process of portfolio management must be integrated with details of task accomplishment (Laslo, 2010). Lopes and de Almeida (2015) presented an assessment of synergies for choosing a project portfolio in the petroleum industry based on a multi-attribute utility function. Patanakul (2015) defined key attributes of effectiveness in managing project portfolio including strategic alignment, adaptability to internal as well as external changes and the expected value of the portfolio. Many project portfolio selections are formulated as mixed integer programming and we need to use metaheuristics to find the near optimal solution for them (vom Brocke \& Lippe, 2015). Rabbani et al. (2010), for instance, presented a multi-objective particle swarm optimization for project selection problem.

\section{The proposed method}

In this section, we present details of the mathematical model for the proposed study. This paper presents a scenario based mathematical model for project portfolio selection when parameters are under uncertainty. The problem considers two objective functions where the first one maximizes the net present value while the second objective function is the minimization of the positive deviations from the allocation of resources. The second objective function is looking for project resource leveling.

\section{Indices}

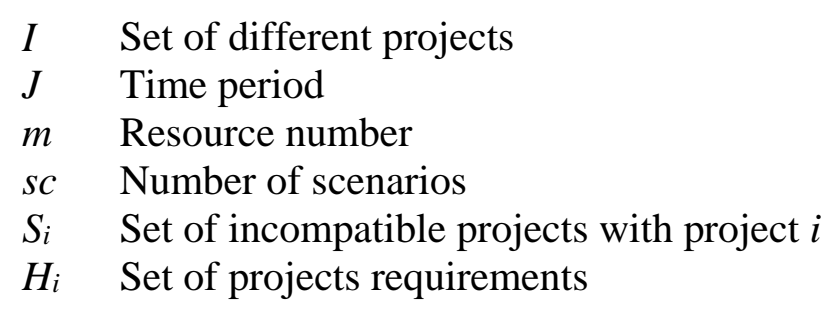

\section{Parameters}

$N \quad$ Total number of projects

$T \quad$ Total amount of available time

$M \quad$ Total number of resources

B Total available budget

$r \quad$ Interest rate

$d_{i} \quad$ Duration of each project

$\Pi_{s c} \quad$ The likelihood of each scenario

$M_{j} \quad$ Amount of available resource at time $j$

$R_{i m} \quad$ Amount of required resource $M$ for accomplishment of project $i$

$C_{m j s c}$ Cost of using resource $m$ at time $j$ under scenario $s c$

$P_{i j s c} \quad$ Revenue of using resource $m$ at time $j$ under scenario $s c$ 


$$
\begin{aligned}
& x_{i j}=\left\{\begin{array}{lr}
1 & \text { if project } i \text { at time } j \text { is selected } \\
0 & \text { otherwise }
\end{array}\right. \\
& y_{i j}= \begin{cases}1 & \text { if project } i \text { at time } j \text { is executed } \\
0 & \text { otherwise }\end{cases}
\end{aligned}
$$

Objective function

$$
\begin{aligned}
& z_{1}=\max \sum_{s c=1}^{S} \pi_{s c}\left[\sum_{i=1}^{N} \sum_{j=1}^{T} \frac{P_{i j s c}}{(1+r)^{j}} x_{i j}-\sum_{i=1}^{N} \sum_{j=1}^{T} y_{i j} \sum_{m=1}^{M} \frac{R_{i m} C_{m j s c}}{(1+r)^{j}}\right] \\
& z_{2}=\min \sum_{j=1}^{T-1}\left|\sum_{i=1}^{N} \sum_{m=1}^{M} R_{i m}\left(y_{i j}-y_{i, j+1}\right)\right|
\end{aligned}
$$

\section{Constraints}

$$
\begin{aligned}
& \sum_{j=1}^{T} x_{i j} \leq 1 \quad \forall i \in I \\
& \sum_{j=1}^{T} j \times x_{i j}+d_{i} \leq T+1 \quad \forall i \in I \\
& \sum_{j=1}^{T}\left(x_{i j}+x_{r j}\right) \leq 1 \quad \forall i \in I, r \in S_{i} \\
& \sum_{s c=1}^{S} \pi_{s c} \sum_{i=1}^{N} \sum_{j=1}^{T} y_{i j} \sum_{m=1}^{M} \frac{R_{i m} C_{m j s c} \leq B}{(1+r)^{j}} \leq B \\
& \sum_{j=1}^{T} x_{i j} \leq \sum_{j=1}^{T} x_{l j} \quad \forall i \in I, l \in H_{i} \\
& \sum_{j=1}^{T} y_{i j} \leq d_{i} \quad \forall i \in I \\
& \sum_{k=j}^{j+d_{i}-1} y_{i k}-d_{i} x_{i j} \geq 0 \quad \forall i \in I, k, j \in J \quad j \leq T-d_{i}+1 \\
& d_{i} \sum_{j=1}^{T} x_{i j}=\sum_{j=1}^{T} y_{i j} \quad \forall i \in I \\
& R_{i m} y_{i j}+\sum_{m=1}^{M} \sum_{h=1}^{N} y_{h j} R_{h m} \leq M_{j} \quad \forall i \in I, j \in J, h \neq i \\
& x_{i j}, y_{i j} \in\{0,1\}
\end{aligned}
$$

The first objective function given in Eq. (1) represents the maximization of total net present value while the second objective function, Eq. (2), is the minimization of the positive deviations from the allocation of resources. In fact, the second objective function is looking for project resource leveling. Eq. (3) states that each project has to be executed once. Eq. (4) specifies that each project has be finished based on scheduled time. Eq. (5) demonstrates any possible inconsistency for occurrence of each project. Eq. (6) shows the amount of budget, which must be used at most. Eq. (7) shows the prerequisite relationships between some of the projects. Eqs. (8-11) are used to ensure that all projects are executed according to time schedule and finally, Eq. (12) indicates the nature of variables, which are binary. As we can observe, the second objective function is nonlinear and we replace $z_{2}=v^{+}+v^{-}$where $v^{+}, v^{-} \geq 0$ and 


$$
\sum_{j=1}^{T-1} \sum_{i=1}^{N} \sum_{m=1}^{M} R_{i m}\left(y_{i j}-y_{i, j+1}\right)=v^{+}-v^{-} .
$$

Eq. (13) helps us convert the problem statement into linear form and we may use a mixed integer programming technique to solve this problem. In addition, to solve the resulted multi objective decision making problem, we use $\varepsilon$-constraint technique (Mavrotas, 2009).

\section{Results and implementation}

In order to examine the performance of the proposed study, we have used two examples, one in small size and the other in large size.

\subsection{Example one}

Consider a company that wishes to arrange the best project portfolio for the next ten years with 1 million dollar budget. There are five projects and project 1 and 3 cannot be executed together and interest rate is $22 \%$. Moreover, there are three scenarios of optimistic, normal and pessimistic with the possibilities of 30, 50 and 20 percent, respectively. Table 1 and Table 2 present other necessary information.

\section{Table 1}

Time and resources needed for execution of each project

\begin{tabular}{lccc}
\hline & & \multicolumn{2}{c}{ Resources needed } \\
\cline { 3 - 4 } Project & Completion time & Manpower & Raw material \\
\hline 1 & 2 & 2 & 3 \\
2 & 5 & 2 & 7 \\
3 & 2 & 7 & 6 \\
4 & 3 & 3 & 5 \\
5 & 5 & 1 & 6 \\
\hline
\end{tabular}

Table 2

Amount of available resources

\begin{tabular}{lcccccccccc}
\hline Year & 1 & 2 & 3 & 4 & 5 & 6 & 7 & 8 & 9 & 10 \\
\hline Manpower & 11 & 16 & 14 & 12 & 16 & 16 & 17 & 18 & 19 & 10 \\
\hline $\begin{array}{l}\text { Raw } \\
\text { material }\end{array}$ & 18 & 15 & 13 & 16 & 16 & 24 & 25 & 26 & 16 & 26 \\
\hline
\end{tabular}

Using the information of Table 1 and Table 2 we have solved the mixed integer programming problem. The final results indicate that we should execute only project 2 first and then complete project 5 . The objective functions are $\mathrm{Z}_{1}=22087.274$ and $\mathrm{Z}_{2}=2$.

\subsection{Example 2}

Now consider the same firm with 15 years of planning and 10 million dollars budget. The pairs of the inconsistent projects $i-j$ include 1-3, 1-9, 5-7, 8-9 and 12-13. Moreover, complete execution of the first project is necessary for 9,3 for 7,5 for 10 and 9 for 13 . Other conditions are the same Example 1 . Table 3 and Table 4 present the summary of resources needed. 
Table 3

Time and resources needed for execution of each project

\begin{tabular}{|c|c|c|c|}
\hline \multirow{2}{*}{ Project } & \multirow{2}{*}{ Time } & \multicolumn{2}{|c|}{ Resources required } \\
\hline & & Manpower & Raw material \\
\hline 1 & 7 & 2 & 9 \\
\hline 2 & 8 & 6 & 7 \\
\hline 3 & 6 & 3 & 6 \\
\hline 4 & 7 & 6 & 5 \\
\hline 5 & 5 & 1 & 7 \\
\hline 6 & 9 & 6 & 9 \\
\hline 7 & 4 & 9 & 8 \\
\hline 8 & 7 & 9 & 7 \\
\hline 9 & 3 & 8 & 8 \\
\hline 10 & 7 & 5 & 6 \\
\hline 11 & 6 & 5 & 11 \\
\hline 12 & 12 & 3 & 3 \\
\hline 13 & 11 & 9 & 12 \\
\hline 14 & 4 & 4 & 4 \\
\hline 15 & 10 & 7 & 7 \\
\hline
\end{tabular}

\section{Table 4}

Amount of available resources

\begin{tabular}{lccccccccccccccc}
\hline \multicolumn{1}{c}{ Year } & 1 & 2 & 3 & 4 & 5 & 6 & 7 & 8 & 9 & 10 & 11 & 12 & 13 & 14 & 15 \\
\hline $\begin{array}{l}\text { Manpower } \\
\text { Raw } \\
\text { material }\end{array}$ & 11 & 11 & 7 & 12 & 12 & 8 & 12 & 13 & 8 & 10 & 12 & 13 & 12 & 13 & 13 \\
\hline
\end{tabular}

Again, we have solved the resulted problem using a mixed integer programming solver and the results were $Z_{1}=32743.778$ and $Z_{2}=1$. We need to first completely execute the third project, then project 5 followed by project 14 . The preliminary results indicate that we may increase profitability by considering different scenarios instead of one single scenario. In this model, different scenarios have been considered for income and expenses and the proposed model has considered all possible scenarios in an integrated model. We believe an integrated model may reduce the expenses, which could eventually reduce the risk of possible loss.

\section{Conclusion}

In this paper, we have presented a new mathematical model for project portfolio selection by considering different scenarios. The proposed study of this paper has been formulated as a multi objective decision making problem with one nonlinear function. The resulted model has been linearized and using $\varepsilon$-constraint technique, the proposed model has been solved for some numerical instances. The preliminary results indicate that we may increase profitability by considering different scenarios instead of one single scenario.

\section{Acknowledgement}

The authors would like to thank the anonymous referees for constructive comments on earlier version of this paper.

\section{References}

Abbassi, M., Ashrafi, M., \& Tashnizi, E. S. (2014). Selecting balanced portfolios of R\&D projects with interdependencies: a cross-entropy based methodology. Technovation, 34(1), 54-63. 
Bardhan, I. R., Kauffman, R. J., \& Naranpanawe, S. (2010). IT project portfolio optimization: a risk management approach to software development governance. IBM Journal of Research and Development, 54(2), 2-1.

vom Brocke, J., \& Lippe, S. (2015). Managing collaborative research projects: A synthesis of project management literature and directives for future research. International Journal of Project Management, 33(5), 1022-1039.

Chiang, I. R., \& Nunez, M. A. (2013). Strategic alignment and value maximization for IT project portfolios. Information Technology and Management, 14(2), 143-157.

Davoudpour, H., Rezaee, S., \& Ashrafi, M. (2012). Developing a framework for renewable technology portfolio selection: A case study at a R\&D center. Renewable and Sustainable Energy Reviews, 16(6), 4291-4297.

Ghorbani, S., \& Rabbani, M. (2009). A new multi-objective algorithm for a project selection problem. Advances in Engineering Software, 40(1), 9-14.

Golmakani, H. R., \& Fazel, M. (2011). Constrained portfolio selection using particle swarm optimization. Expert Systems with Applications, 38(7), 8327-8335.

Golmohammadi, A., \& Pajoutan, M. (2011). Meta heuristics for dependent portfolio selection problem considering risk. Expert Systems with Applications,38(5), 5642-5649.

Hai-xiang, Y., \& Zhong-fei, L. (2009). Portfolio selection with different borrowing-lending rates: Utility maximization model based on mean and VaR. Systems Engineering-Theory \& Practice, 29(1), 22-29.

Hassanzadeh, F., Nemati, H., \& Sun, M. (2014). Robust optimization for interactive multiobjective programming with imprecise information applied to R\&D project portfolio selection. European Journal of Operational Research,238(1), 41-53.

Huang, X., \& Qiao, L. (2012). A risk index model for multi-period uncertain portfolio selection. Information Sciences, 217, 108-116.

Kaiser, M. G., El Arbi, F., \& Ahlemann, F. (2015). Successful project portfolio management beyond project selection techniques: Understanding the role of structural alignment. International Journal of Project Management, 33(1), 126-139.

Kloppenborg, T. (2014). Contemporary project management. Cengage Learning.

Laslo, Z. (2010). Project portfolio management: An integrated method for resource planning and scheduling to minimize planning/scheduling-dependent expenses. International Journal of Project Management, 28(6), 609-618.

Liesiö, J., Mild, P., \& Salo, A. (2008). Robust portfolio modeling with incomplete cost information and project interdependencies. European Journal of Operational Research, 190(3), 679-695.

Lopes, Y. G., \& de Almeida, A. T. (2015). Assessment of synergies for selecting a project portfolio in the petroleum industry based on a multi-attribute utility function. Journal of Petroleum Science and Engineering, 126, 131-140.

Mavrotas, G. (2009). Effective implementation of the $\varepsilon$-constraint method in multi-objective mathematical programming problems. Applied mathematics and computation, 213(2), 455-465.

Müller, M. P., Meier, C., Kundisch, D., \& Zimmermann, S. (2015). Interactions in IS project portfolio selection-status quo and perspectives. Interactions, 3, 5-2015.

Patanakul, P. (2015). Key attributes of effectiveness in managing project portfolio. International Journal of Project Management, 33(5), 1084-1097.

Rabbani, M., Bajestani, M. A., \& Khoshkhou, G. B. (2010). A multi-objective particle swarm optimization for project selection problem. Expert Systems with Applications, 37(1), 315-321.

Rahmani, N., Talebpour, A., \& Ahmadi, T. (2012). Developing a multi criteria model for stochastic IT portfolio selection by AHP method. Procedia-Social and Behavioral Sciences, 62, 1041-1045.

Solak, S., Clarke, J. P. B., Johnson, E. L., \& Barnes, E. R. (2010). Optimization of R\&D project portfolios under endogenous uncertainty. European Journal of Operational Research, 207(1), 420433.

Vilkkumaa, E., Liesiö, J., \& Salo, A. (2014). Optimal strategies for selecting project portfolios using uncertain value estimates. European Journal of Operational Research, 233(3), 772-783. 